\title{
COLLABORATIVE AIR QUALITY MAPPING OF DIFFERENT METROPOLITAN CITIES OF INDIA
}

\author{
Rakesh Dubey ${ }^{1, *}$, Shruti Bharadwaj ${ }^{1}$, MD Iltaf Zafar ${ }^{1}$, Susham Biswas ${ }^{1}$ \\ ${ }^{1}$ Dept. of Chemical Engineering and Engineering Sciences, Rajiv Gandhi Institute of Petroleum Technology Jais, Amethi, \\ Uttar Pradesh, INDIA- (pgi19001, pgi17001, mzafar, susham)@rgipt.ac.in
}

KEYWORDS: Air pollution, air quality mapping, Dispersion, GIS Mapping, Interpolation, Modeling, Road Traffic

\begin{abstract}
:
Environmental pollution has become extremely serious as a result of today's technological advancements all over the world. One of the most important environmental and public health risks is air pollution. The exponential growth of population, vehicular density on highways, urbanization, and other factors are rising air pollution in cities, necessitating techniques for monitoring and forecasting air quality or determining its health consequences. Various experiments are being conducted on city air quality and its distribution through the built climate. The amount of emissions in the air varies according to the time of day as depicted it is merely high in morning time between 9 to 10 am and between 5 to $6 \mathrm{pm}$ in all cities. These collected data are also characterized as peak hour, average hour, and off-peak hour. It also varies geographically and during special occasions. Since computing and showcasing of air pollution levels require terrain data, air quality data from the open sources i.e. CPCB (central pollution control board, India), and air pollution prediction models. Acculumating the data of the air pollution parameter from the open sources of cities based on typically very crowded, averagely crowded, and thinly crowded areas across the city and then mapping it on ArcGIS. The data monitoring has been done for the whole year merely main emphasizes has been done on the three seasons autumn, winter, and summer (January, May, and August). Also, in winter the value of having pollutants is high due to winter inversion and in the morning also the value is higher, and in monsoon, due to precipitation, it decreases. The dispersion model help in considering the wind speed and direction, the computed data from each source location reaching out to the monitoring sensing station from the comparatively adding to the value of pollutant. With the help of questionnaires, computed out to the result that people residing or having the workplace near to the busy crossing are more promising to have the health-related issue like chocking, respiratory diseases. Men are merely more affected by this between the age of 37 to 63 years.
\end{abstract}

\section{INTRODUCTION}

Air pollution is a widespread problem that poses serious health risks. We are progressing towards modernization as technology advances. Using the most appropriate technologies makes our lives simpler and more convenient (Tandel and Sonaviya 2018). However, with this advancement and progress, many health hazards are associated with it, newer innovations or advancements are often linked to health risks. Chronic exposure to indoor air emissions for a long period can be harmful to one's wellbeing, and air pollution is a major environmental problem that mainly affects the health of urban communities. Increasing the amount of time, you spend outside raises the chance of contracting an airborne illness. Cardiovascular and respiratory disorders, to name a few. Lung cancer is a form of cancer that affects (Babisch and Van Kamp 2009). In comparison to developed nations, health conditions are more prevalent in emerging countries.

The main aim in terms of public health is to raise public consciousness so that people can take practical measures to protect themselves from the adverse effects of air pollution. A secondary aim is to increase awareness of the effects of existing levels of air emissions to inspire changes in human behavior and public policy. Children, the elderly, those engaged in physical activities, and those suffering from heart or lung disease are all examples. In most cases, an AQI is made up of many sub-indices for different contaminants. O3, $\mathrm{NOx}, \mathrm{COx}$, and $\mathrm{SO} 2$ are the most common contaminants considered.

Scientific and regulatory bodies are working to measure the decline in the air quality standards in metropolitan cities. With the increase in the number of vehicles and pollution through them, the air quality has changed drastically over time.
Measuring the level of decline in the air quality standard is a time-consuming, complicated and expensive forum. Monitoring depicts the level of air pollution at a specific location. A geographic information system (GIS) is based on the interpolation of geographically constrained data that allows you to store, analyze, and visualize geographic data (Bocher et al. 2019). Various researchers have used GIS techniques to investigate the space and time-constrained distribution of contaminants. Air contamination has been assessed as a health concern in many countries performed ordinary Kriging spatial interpolation using tracked air quality data. has done a comparison of different spatial interpolation methods and find out that the IDW (with power 2) gives the best-suited result. India is attempting to reduce the impact to a manageable degree by reporting, assessing, and informing the public about its negative consequences.

Air quality simulations have been used in several experiments to map air quality and assess health effects. Emission data for all known sources of pollution are needed for air quality modeling. When estimating ground-level concentrations, dispersion models are thought to have a high degree of ambiguity due to different types of assumptions as well as the model's input data consistency. In addition, simulation requires onsite hourly meteorological data for various parameters, which is not always feasible. As a result, the observed air quality was used in this study. Authorities instituted some control mechanisms as a result of public pressure, which necessitated a collaborative initiative. As a result, air quality improved between 1991 and 2003. According to the National Environment Engineering Research Institute (NEERI), various studies indicate that suspended particulate matter (SPM) and PM10 levels are far higher than the Central Pollution Control Board's requirements (CPCB) 
(Banerjee et al. 2008). SPM and PM10 levels in suburban areas are 140 and $60 \mathrm{~g} / \mathrm{m} 3$, respectively.

\section{LITERATURE REVIEW}

\subsection{Satellite image-based Air quality Mapping}

Air quality mapping is crucial for educating the public about pollution levels in different areas. Various sources of air quality data, including in-situ measurements, air quality models, and satellite observations, may be used for this purpose. However, due to significant data gaps, inadequate spatial resolution, or major uncertainties, none of these data sources are entirely adequate for mapping purposes on their own. As part of the SAMIRA (Gupta, Kumar, and Yuga Raju 2019), the author has tried to combine these different data sources using data fusion techniques to provide more accurate knowledge within air quality mapping. At separate temporal resolutions, we looked at three contaminants (NO2, PM10, and PM 2.5). (annual, daily, hourly). Spatial and temporal data differences are common in satellite data. The gaps were then filled using the Gap-fill package in R to perform the spatial-temporal interpolation. In comparison to mapping using only in-situ and model data, our current findings show that including satellite measurements in air quality mapping may provide some improvement in terms of root mean square error and bias (Jana et al. 2018).

Both living species are adversely affected by air pollution. It causes diseases that are harmful to humans, livestock, and plants. Vehicle traffic has begun to rise as a result of increased vehicle movement, industrialization, and urbanization, causing more harm to people living near industries. A systematic comparative analysis of air pollution and human health was conducted in this study. It was investigated with the help of a Geographical Information System (GIS) and a digital topographical map created with Arc GIS software.

In this investigation, the relationship of satellite and groundbased data observation of air quality assessment in the city of Canada is shown. They were both linked to coincident groundbased ozone concentrations (GOC) and fine real matter levels in both the summer and winter seasons (PM2.5)(Tian and Chen 2007). AOD was found to be the most closely related to coincident hourly PM2.5 in the summer, while TOB and coincident hourly GOC had a similar association (Tian and Chen 2007).

Air quality mapping is done by using Geographic Information Systems, the amounts of coarse particulate matter (PM10) in Baguio City's Central Business District are assessed. According to the news, Baguio City is one of the country's most polluted cities, and several surveys have been conducted to test its air quality. The results of dispersion simulation, i.e., PM10 concentrations per 20 meters, show that high values range from 135 to $422 \mathrm{~g} / \mathrm{mm} 3$. Pollutant amounts are detectable within 40 meters of the tracks. To measure spatial variations and PM10 figures at unsampled sites, ordinary Kriging is used. Suggested mean error (ME), root mean square error (RMSE), and standardized error values are used to evaluate geostatistical modeling estimates. To refine pollutant concentration estimates, produce surface representations can be used in combination with atmospheric dispersion models (Gupta et al. 2019).

In 2005, Model findings are evaluated using in situ validation against tracking data. Methodological uncertainty must be considered when using model output in a policy context, as shown in this case study. The model's specificity for respirable particulate matter (PM10) concentrations is $10 \%$, as is the 90th percentile of daily mean PM10, with a bias of 0 to $+12 \%$. (Overprediction by the model). As predicted, the high and 99.8 percent of hourly mean nitrogen dioxide concentrations, as well as total NOx, are less reliable. We consider using probabilistic mapping techniques to better understand how uncertainty is translated into the concept of an Air Quality Management Area (AQMA) on a globe. (Ramos and Blanco 2019).

This GIS-based mapping has exploded in popularity in upcoming years, with applications in virtually every area and a focus on expanding spatial data. GIS-based air quality mapping has become a very valuable instrument in terms of noise emissions, which can be a serious health problem (Dubey, Bharadwaj, and Biswas 2020). It provides numerically simulated results, as well as tools designed specifically for environmental air quality mapping applications. The GIS-based estimation is carried out in the background, with adequate visualization and analysis, and it is embedded in the spatial domain. It is necessary to determine when, where, and how this analysis will be conducted. Once the predicted air maps have been developed, they must be correlated spatially to determine relative impacts. This chart must also be related to people's fears about their health as a result of air pollution.

\subsection{Web-based GIS Mapping}

The web-based GIS framework's primary goal is to provide a quick and intuitive interface for users to generate maps from ArcGIS and display them on the web. Users can access the internet from this location. On the internet, parameters are uploaded, where they are spatially referenced and mapped. It also allows users to exchange files that can be easily tracked over the internet. ArcGIS has only four major components: a geographically based modeling model, various components for storing and managing geographic data, and third, various components for storing and managing geographic data. Finally, there's the online services range, which provides content and functionality to networked software customers (Maguire 2016). ArcGIS makes it simple to analyze field data. We can use symbols and classifications to represent and classify our data, as well as perform spatial analysis. We may also create story maps using our results by displaying them online as live site maps, embedding them in websites, and presenting them as live web maps. Esri has created a website where anyone can freely access and use geographic data in a collaborative environment. The Web GIS pattern, which helps all members of an organization to easily access and use geographic details in a shared sense, is one of the main concepts of the Esri Geospatial Cloud. It has user-friendly that allows even inexperienced users to access and contribute to the GIS network. It also makes them more available and discoverable. It offers an integration forum, encourages cross-organizational cooperation, and allows for effective decision-making (Esri 2018).

\section{STUDY AREA}

In the study basically, the mapping of different metropolitan cities of India like Delhi, Chennai, Mumbai, and Kolkata has been done. These cities have different atmospheric conditions and have variations in the city ambiance in respect of the traffic. Here, all the three metro Politian cities are considered for air quality mapping (Delhi, Mumbai, Kolkata, and Chennai). Delhi is the capital of India and with 32 million people (Census of India Organisation, 2021), this is the most densely populated city in India. The mapping has been done considering the different seasonal variations in the city's temperature and geographical features. The population density and land use pattern in these cities are prominently different from each other. Also, Chennai with the 2011 Indian census, is India's sixth-largest city and fourth-largest metropolitan agglomeration. The Chennai 
Metropolitan Area, which includes the city and its surrounding areas, is the world's 36th-largest urban area by population.

\section{OBJECTIVES}

The authors of this study attempted to determine the level of air quality in various metropolitan cities of varying ambiances and traffic environments. The authors will try to figure out how to: The authors will try to figure out how to:

1. To fulfill a geospatial data gap, use an open-source map.

2. Interpolation is used to produce an air quality map for a region using open-source data from CPCB India.

3. A survey will be conducted in Delhi to determine the population impacted by the negative effects of pollution and to raise awareness among the group.

\section{METHODOLOGY}

For air quality mapping, the authors have selected various metropolitan cities in India. Different forms of traffic environments are available in the area. It was intended to categorize traffic air emissions into various categories and then use the information to map air pollution in the local areas. Furthermore, the mapping would be achieved using data obtained from open-source air quality data. The mapping has been done for three different seasons winter, summer and autumn. Here in these authors have considered Delhi which has a humid subtropical climate. Delhi is the capital of India (India) Temperature, runoff, and daylight hours averages Delhi, India's capital, has a subtropical climate with a warm and sunny winter, a scorching summer from mid-March to mid-June (before the monsoon), and a muggy and humid summer due to the monsoon. On the other hand, Chennai experiences dry spells in February, March, and April. May is the hottest month, with an average maximum temperature of 37 degrees Celsius (98 degrees Fahrenheit). With an average maximum temperature of is comparatively very low, January is the coldest month. The wettest month is November (Kumar et al. 2018).

\subsection{Computations}

The various computation that is been used for mapping to get the best-suited results.

\subsubsection{Inverse distance weighted interpolation}

Where,

$$
\begin{gathered}
x^{*}=\frac{w_{1} x_{1}+w_{2} x_{2}+w_{3} x_{3}+\cdots+w_{n} x_{n}}{w_{1}+w_{2}+w_{3}+\cdots+w_{n}} \\
N_{O}=\frac{\sum_{i=1}^{n} N_{i} P_{i}}{\sum_{i=1}^{n} P_{i}} \\
P_{i}=\frac{1}{d_{i}^{k}}
\end{gathered}
$$

$\begin{aligned} \mathrm{x}^{*} & =\text { unknown value at a location } \\ \mathrm{w} & =\text { weight }\end{aligned}$

i $=1,2,3,4 \ldots . . n$

\subsubsection{Kriging interpolation}

Where,

$$
\mathrm{N}_{\mathrm{O}}=\sum_{\mathrm{i}=1}^{\mathrm{n}} \mathrm{W}_{\mathrm{i}} \mathrm{N}_{\mathrm{i}}
$$

No $=$ Noise value to be interpolated at point A (xo, yo),
$\mathrm{Wi}=$ weighted value corresponding to points at $\mathrm{Ni}(\mathrm{xi}, \mathrm{yi})$ that are used in the calculation of No

$\mathrm{Ni}=$ noise values of the reference points used in the calculation

\section{RESULTS}

\subsection{Find the best-suited interpolation method}

The root means the square error is used to find the difference between the estimated parameters and the observed parameters. It is calculated by the formula which finds the standard deviation of residuals where residuals are a measure that defines how far the data points from the regression lines. More globally, the most popular mathematical method of describing non-steady signal waveforms is root-mean-square (RMS) (Society 2014).

\begin{tabular}{|l|l|l|l|}
\hline S.NO. & $\begin{array}{l}\text { INTERPOLATION } \\
\text { METHOD }\end{array}$ & TYPE & $\begin{array}{l}\text { RMS } \\
\text { VALUE }\end{array}$ \\
\hline 1 & IDW interpolation & $\mathrm{k}=1$ & 13.83575 \\
\hline 2 & & $\mathrm{k}=2$ & 13.83575 \\
\hline 3 & & $\mathrm{k}=3$ & 15.67949 \\
\hline 4 & & $\mathrm{k}=4$ & 15.67949 \\
\hline 5 & & $\mathrm{k}=5$ & 17.26685 \\
\hline 6 & Kriging interpolation & spherical & 13.8869 \\
\hline 7 & & Circular & 320.0999 \\
\hline 8 & & Exponential & 13.88104 \\
\hline 9 & & Gaussian & 13.9223 \\
\hline 10 & & Linear & 13.89132 \\
\hline
\end{tabular}

Table 1. Comparison between the RMS value of Kriging and IDW interpolation for different powers.

Here in this mapping is done using the IDW interpolation as the comparison in the RMS value calculated using both the method shows that for the power $\mathrm{k}=2$ the RMS value is low and gives a well-suited result.

The collaborative study was conducted with the aid of public recognition and interest in depicting our previous experience to assess the negative impact of pollution on their wellbeing. Also, various government bodies intervention has made the work more precise as they have enlightened the work with their knowledge and support.

\subsection{Air quality mapping of Delhi and Chennai}

The air quality mapping on ArcGIS of the city of Delhi is been shown in Figures 1 to 9, which comprises three different months and three parameters like PM2.5, NOx, and SOx. Also, variation in the different parameters is been shown with the help of graphs of Chennai, Delhi, Kolkata, and Mumbai.

\subsubsection{Delhi air quality mapping of three seasons}

These are the air quality maps of the Delhi region as shown in the figure. 1 to figure. 9 depicting the variation in particulate in different seasons. The different color pattern use in mapping is 
merely for distinguishing in the form of mapping for three particulates like PM2.5, NOx, and SOx.

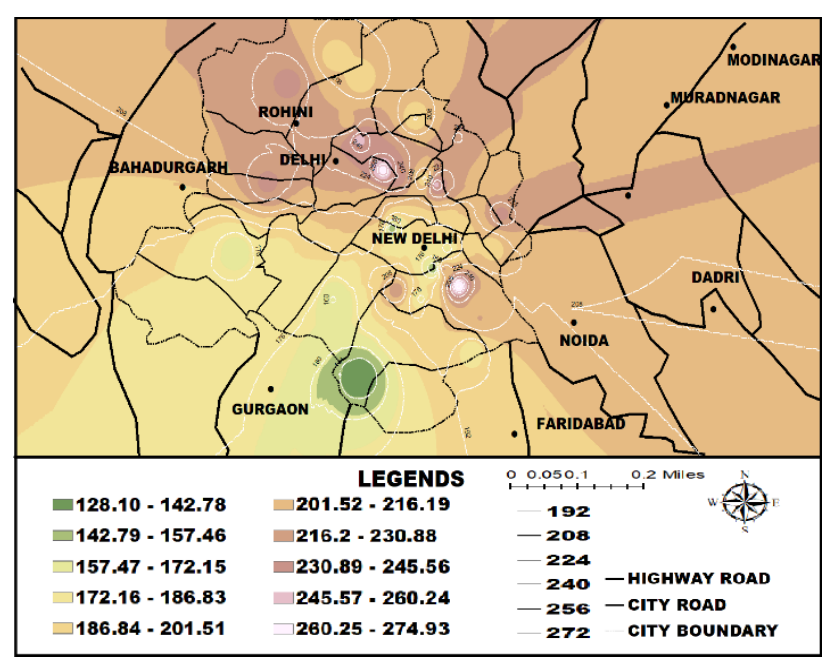

Figure 1. Air quality map of Delhi January monthly average based on PM2.5 $(\mu \mathrm{g} / \mathrm{m} 3)$.

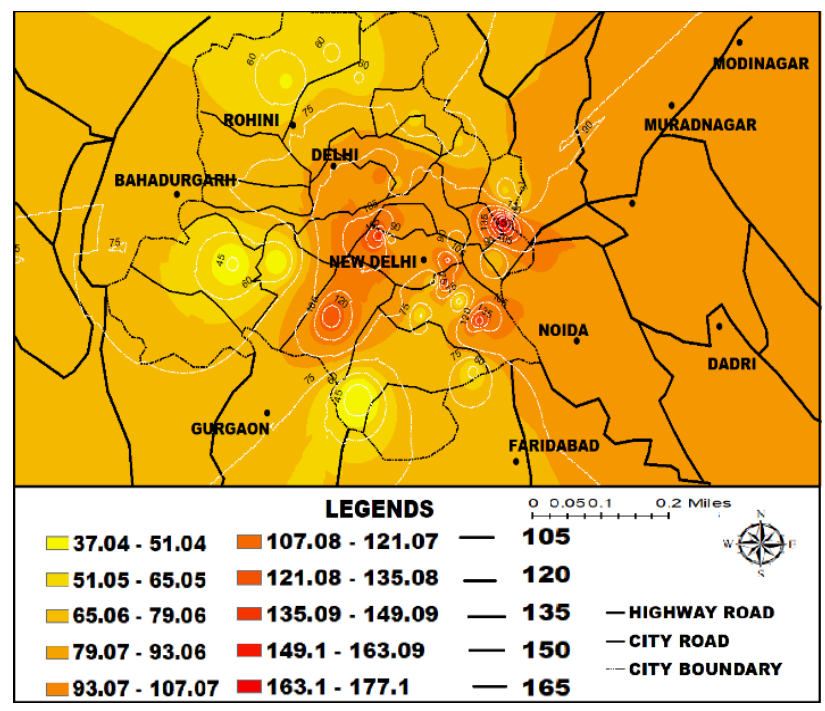

Figure 2. Air quality map of Delhi January monthly average based on NOx $(\mu \mathrm{g} / \mathrm{m} 3)$.

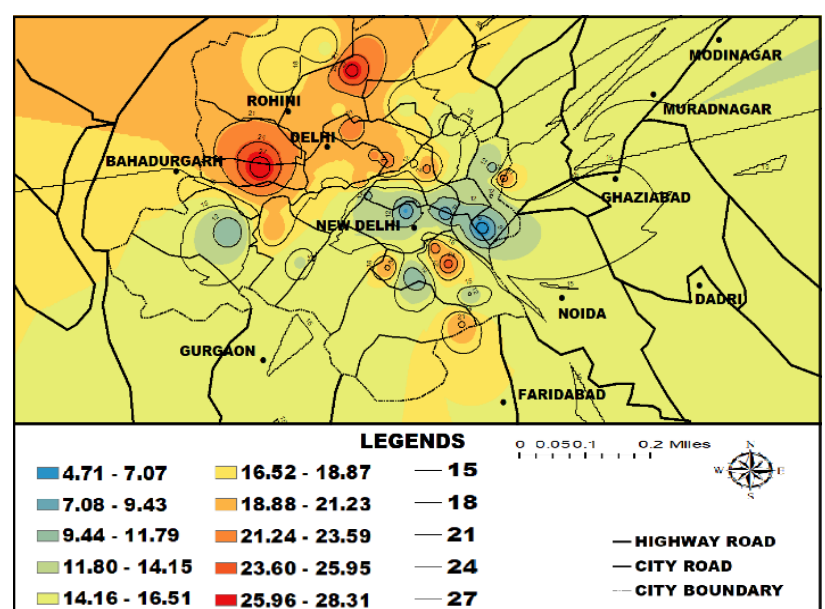

Figure 3. Air quality map of Delhi January monthly average based on $\mathrm{SOx}(\mu \mathrm{g} / \mathrm{m} 3)$.

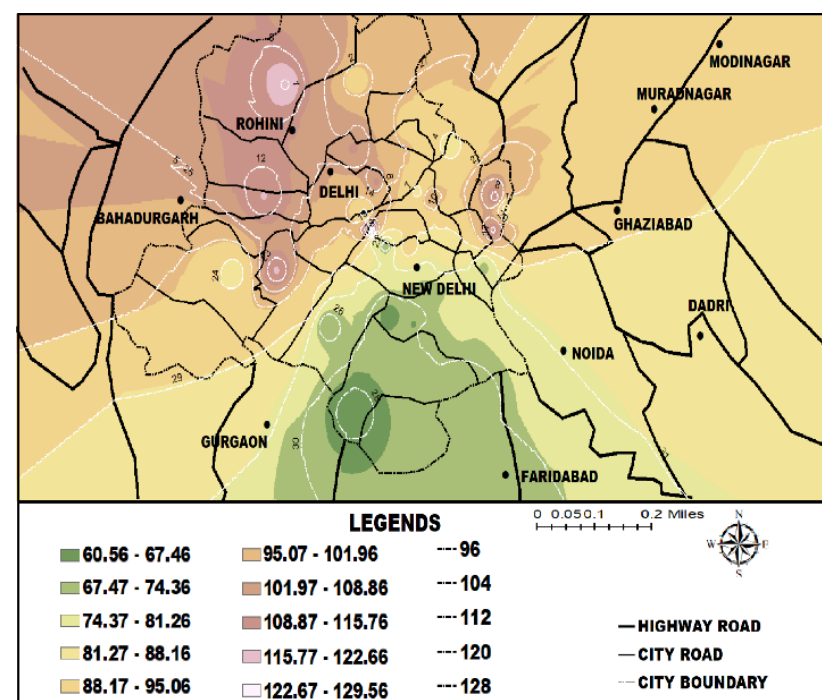

Figure 4. Air quality map of Delhi May monthly average based on PM2.5 $(\mu \mathrm{g} / \mathrm{m} 3)$.

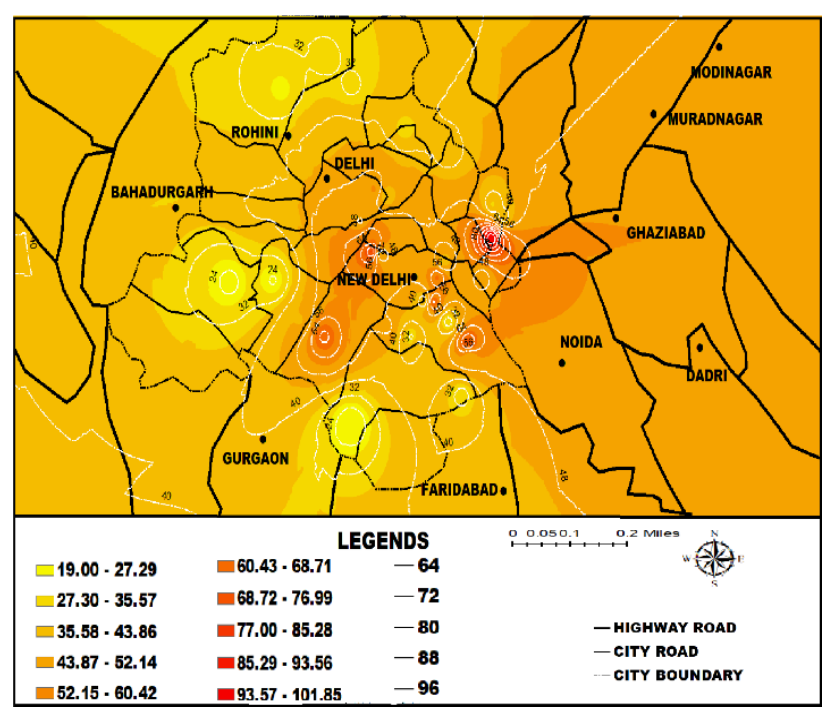

Figure 5. Air quality map of Delhi May monthly average based on NOx $(\mu \mathrm{g} / \mathrm{m} 3)$.

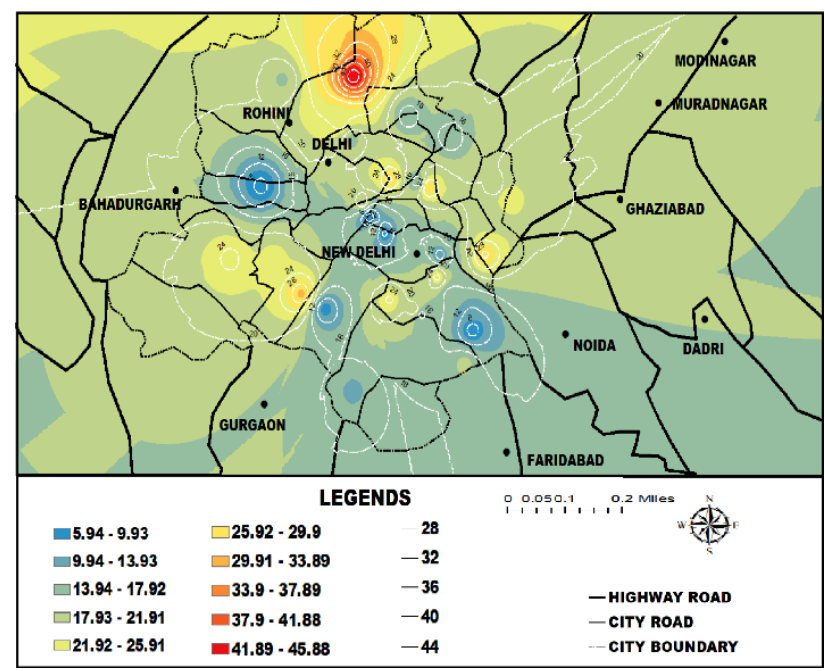

Figure 6. Air quality map of Delhi May monthly average based on $\mathrm{SOx}(\mu \mathrm{g} / \mathrm{m} 3)$. 


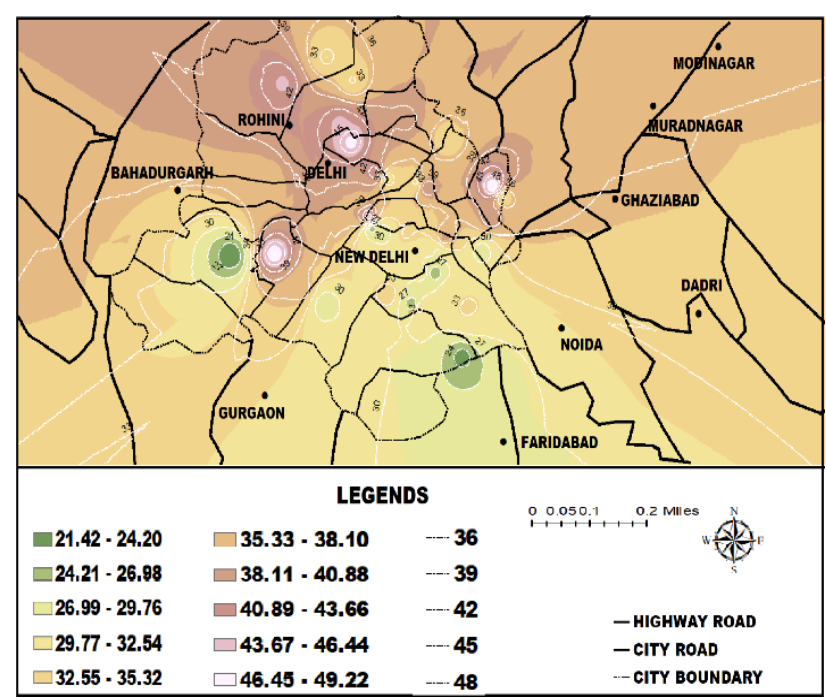

Figure 7. Air quality map of Delhi August monthly average based on PM2.5 $(\mu \mathrm{g} / \mathrm{m} 3)$.

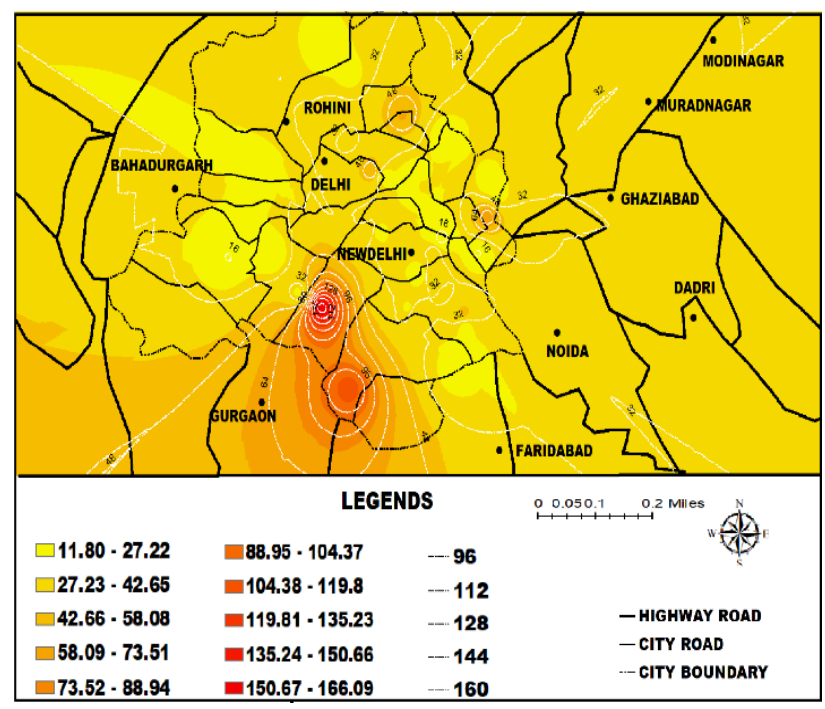

Figure 8 . Air quality map of Delhi August monthly average based on NOx $(\mu \mathrm{g} / \mathrm{m} 3)$.

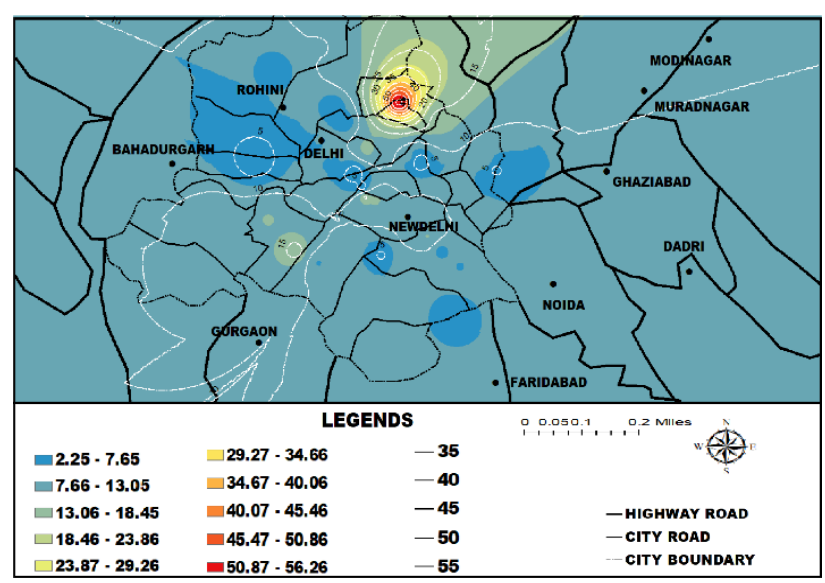

Figure 9. Air quality map of Delhi August monthly average based on $\mathrm{SOx}(\mu \mathrm{g} / \mathrm{m} 3)$.

\subsubsection{Chennai air quality mapping of three seasons}

In respect of the Chennai, which has the drastically different atmospheric condition and has more humidity shows the different results which is been shown in the graph. The graph comprises PM2.5, NOx, and SOx for three different seasons and by the time we can see the change in these air pollutant matters. From Figure 10 to 12 , we can see that the variation is there in all three parameters concerning time for the autumn season.

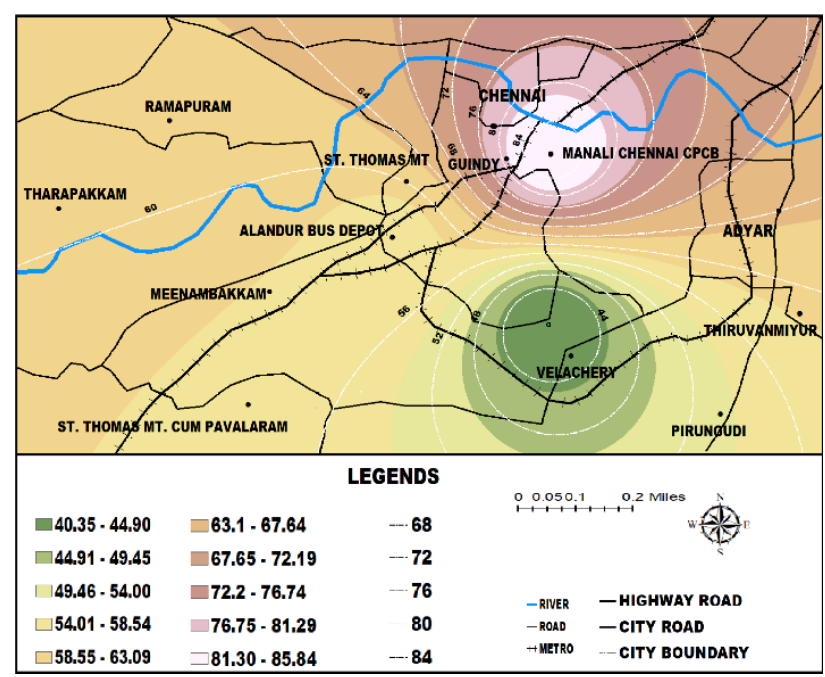

Figure 10. Air quality map of Chennai January monthly average based on PM2.5 $(\mu \mathrm{g} / \mathrm{m} 3)$.

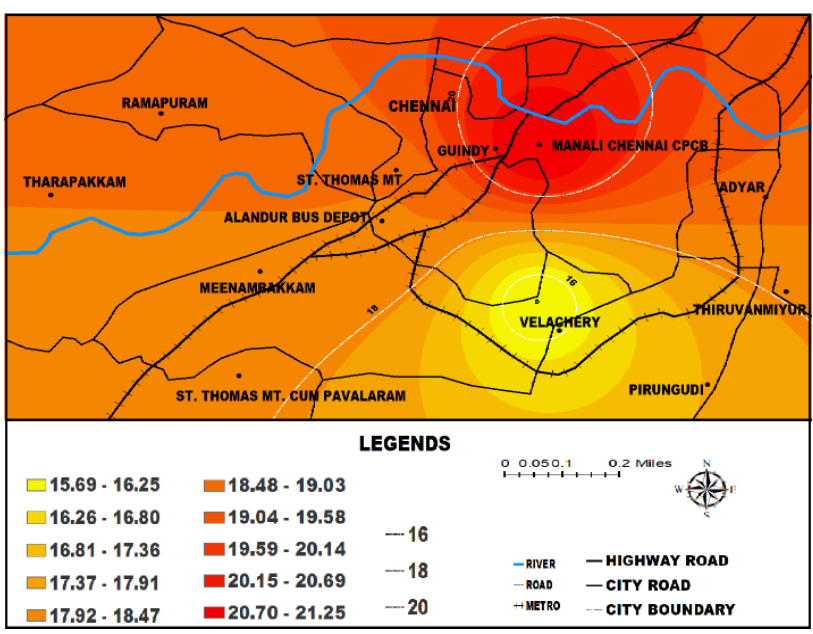

Figure 11. Air quality map of Chennai January monthly average based on NOx $(\mu \mathrm{g} / \mathrm{m} 3)$.

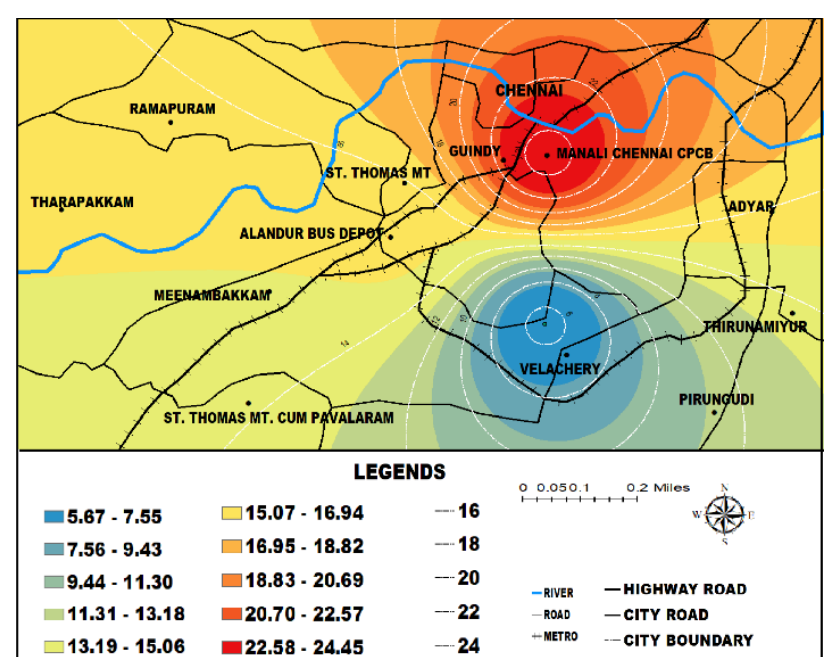

Figure 12. Air quality map of Chennai January monthly average based on SOx $(\mu \mathrm{g} / \mathrm{m} 3)$. 


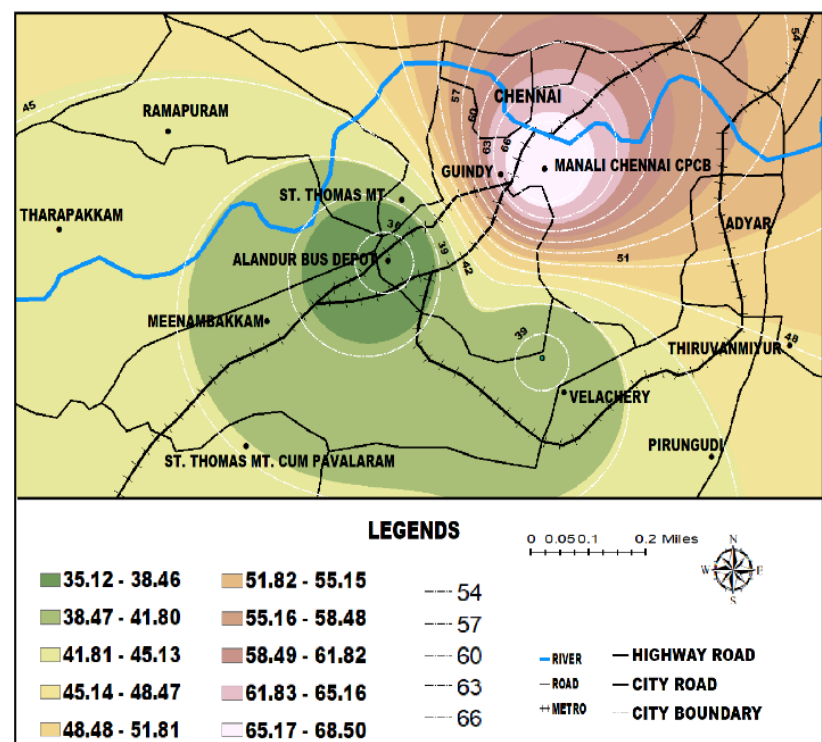

Figure 13. Air quality map of Chennai May monthly average based on PM2.5 $(\mu \mathrm{g} / \mathrm{m} 3)$.

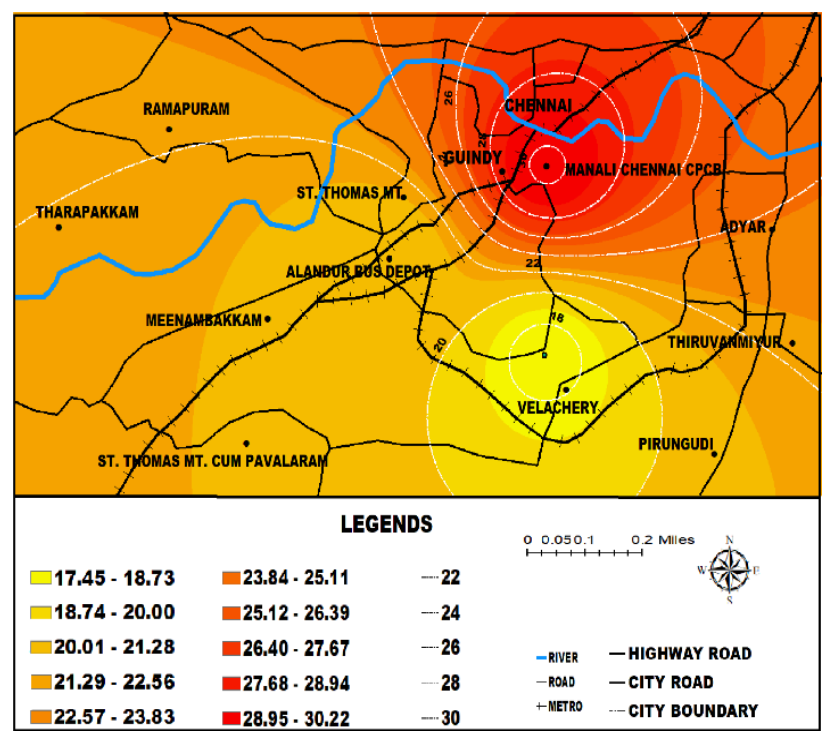

Figure 14. Air quality map of Chennai May monthly average based on NOx $(\mu \mathrm{g} / \mathrm{m} 3)$.

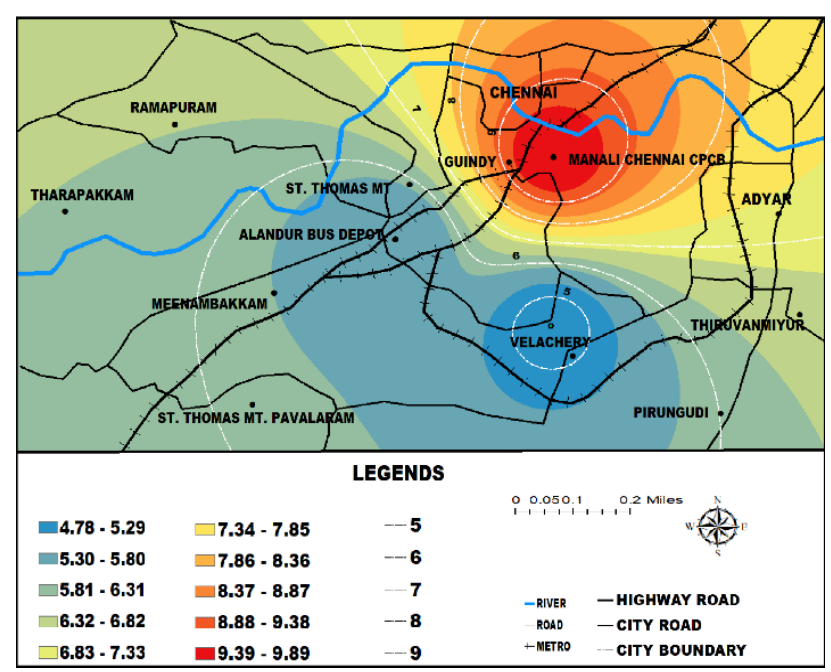

Figure 15. Air quality map of Chennai May monthly average based on SOx $(\mu \mathrm{g} / \mathrm{m} 3)$.

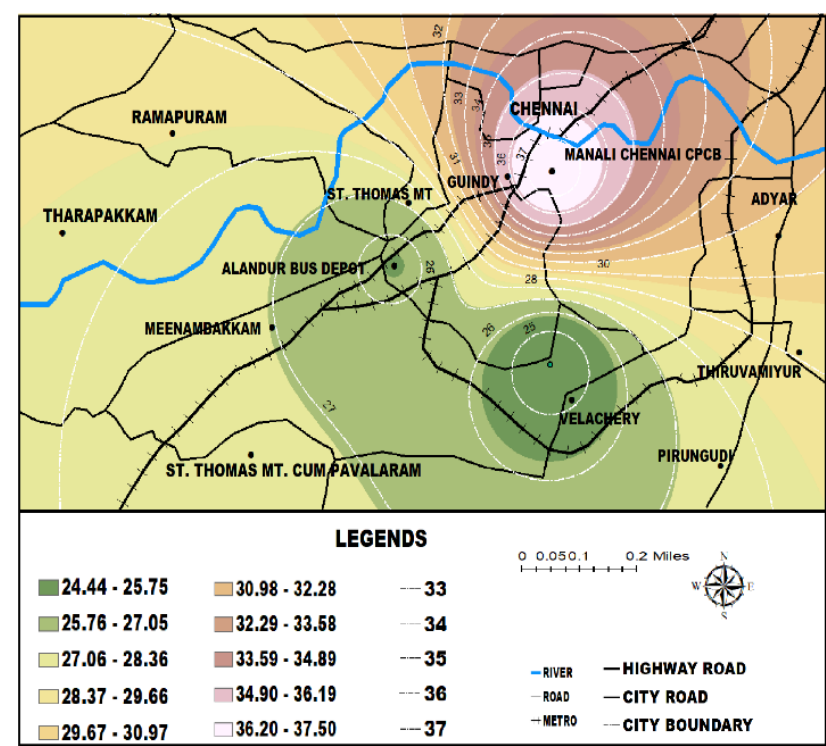

Figure 16. Air quality map of Chennai August monthly average based on PM2.5 $(\mu \mathrm{g} / \mathrm{m} 3)$.

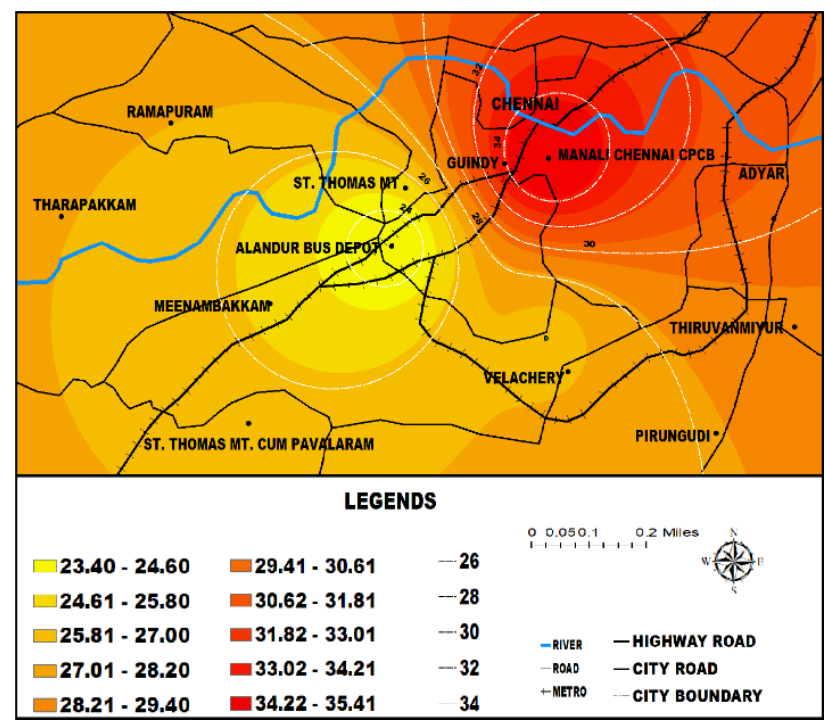

Figure 17. Air quality map of Chennai August monthly average based on NOx $(\mu \mathrm{g} / \mathrm{m} 3)$.

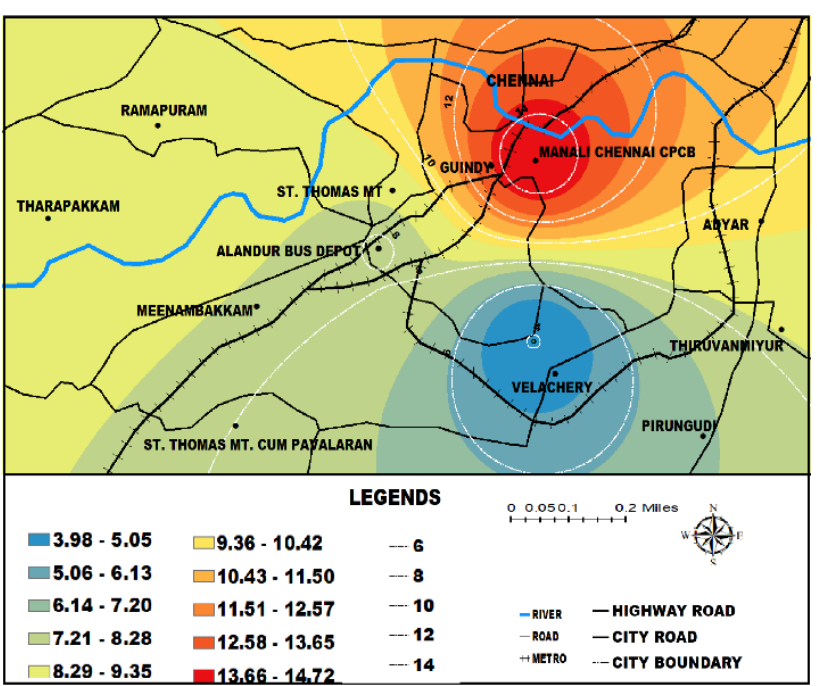

Figure 18. Air quality map of Chennai August monthly average based on SOx $(\mu \mathrm{g} / \mathrm{m} 3)$. 


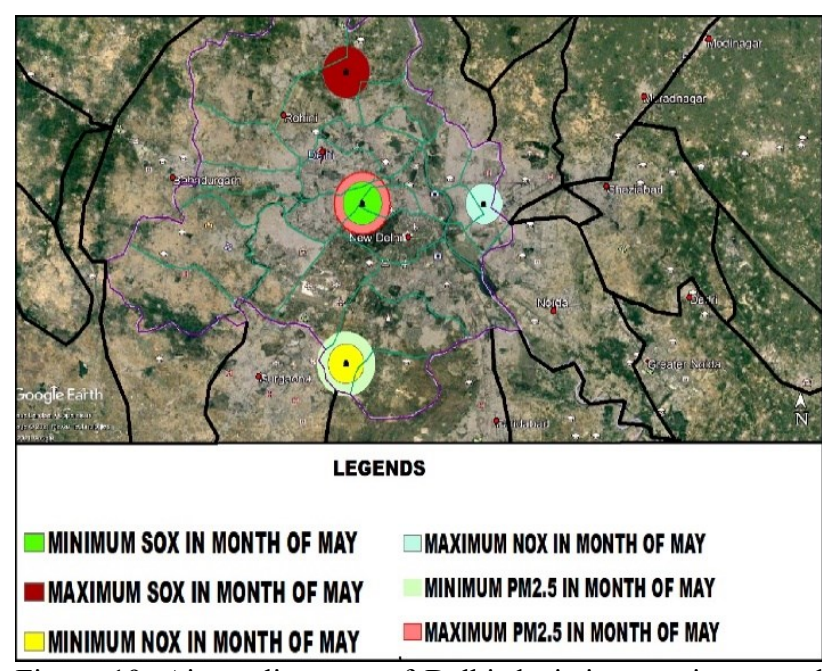

Figure 19. Air quality map of Delhi depicting maximum and minimum value recorded in a different area of Pm2.5, NOx, and SOx in the month of $\operatorname{May}(\mu \mathrm{g} / \mathrm{m} 3)$.

\section{COMPARISON OF POLLUTANT IN FOUR CITIES MONTHLY AVERAGE}

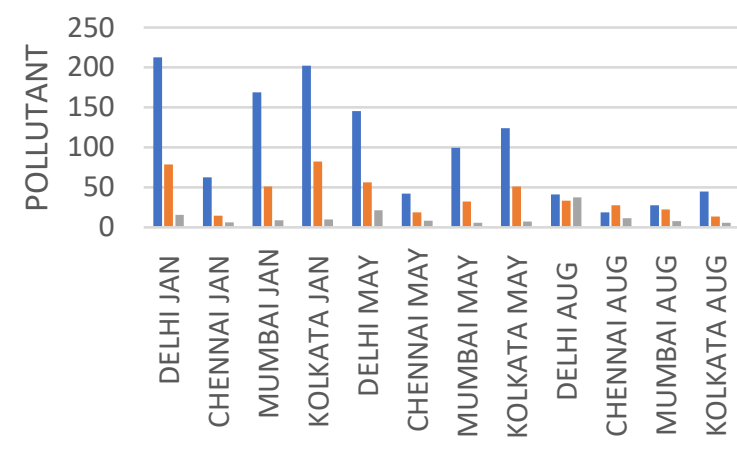

PLACE WITH MONTH

- PM2.5 $(\mu \mathrm{g} / \mathrm{m} 3) \quad$ NOx $(\mu \mathrm{g} / \mathrm{m} 3) \quad$ SOx $(\mu \mathrm{g} / \mathrm{m} 3)$

Figure 20. Comparison of seasonal variation in the Air quality of four different metropolitan cities for a monthly average $(\mu \mathrm{g} / \mathrm{m} 3)$.

From the above comparison, authors can easily predict out that particulate matter 2.5 is merely at a higher note in the month of January. Where else it's merely low in the monsoon that is in the month of August due to precipitation.

\subsection{Delhi air pollution survey with public interaction}

In this case, specific questionnaires were created in conjunction with air quality, and a survey of about 500 people was conducted. This survey was conducted in conjunction with the chosen sites in Delhi where air quality levels vary dramatically during the year. The poll was conducted on men and women of various ages ranging from 14 to 75 years old. Just a handful of the findings have been shown. Here in this mixed approach has been used for depicting out the information in which both quantitative and qualitative approach has been used. Above graphs in the figure. 24, 25 shows the survey done in Delhi about the awareness check in terms of yes or no.

No. of males -290 ( 30 to 75 years)

No. of females -180 (30 to 75 years)

No. of children - 30 (14 to 29 years)

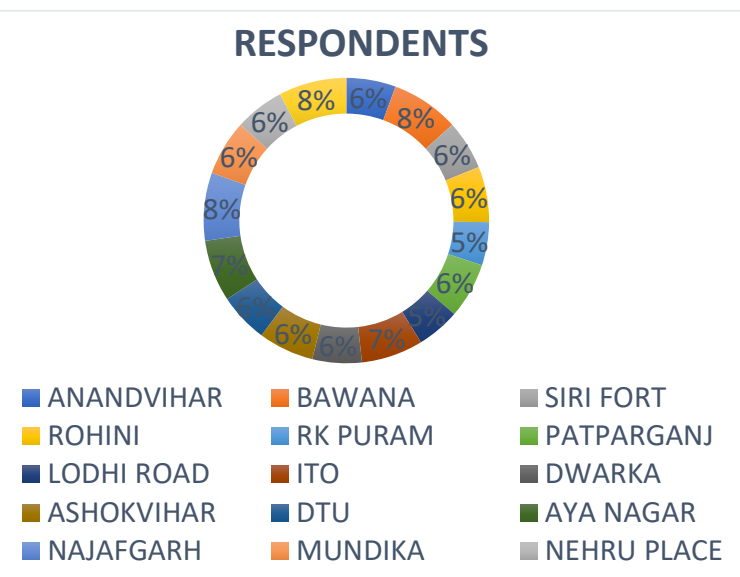

Figure 21. No. of respondents to the survey done in a different part of Delhi in the year 2019

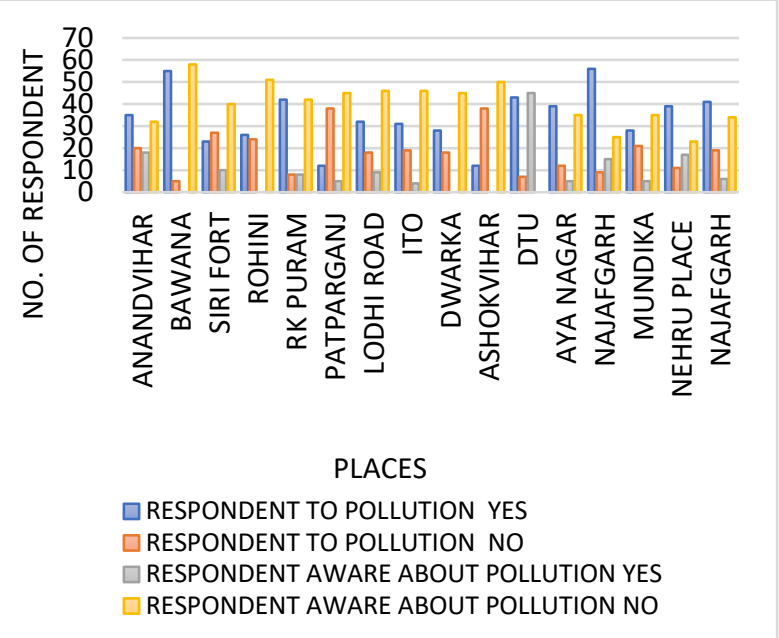

Figure 22. Awareness check in different cities of Delhi about the air pollution and its awareness in terms of respondents.

\section{CONCLUSION}

From the above mapping of Delhi and Chennai respectively author can easily conclude that variation in the values of PM2.5, NOx and SOx are merely at 9 to 10 am which is peak hour for the traffic. The same way it increases at 5 to $7 \mathrm{pm}$ irrespective of the city in consideration of the atmospheric condition and seasonal variation author can conclude that PM2.5, NOx and SOx values are merely high in winters as compared to summer and autumn seasons due to the presence of aerosol particles and fog in the weathers and low-temperature gradient. particulate matter 2.5 is merely at a higher note in the month of January owing to a process known as winter inversion, these toxins are unable to scatter and stay closer to the atmosphere, choking our communities. Summer brings moist, lighter air to the terrestrial boundary layer which grows more quickly. In a method known as "vertical mixing," contaminants are carried away from the earth and mixed with cleaner air in the upper layers of the atmosphere. The same goes for other pollutants this month. In the same way, it decreases in the month of August. Since the effects of inversion are worse at night, air quality drops overnight. During monsoon seasons, wind speed and air temperature are the most significant determinants of PM2.5, while rainfall and 
relative humidity mainly influence daily fluctuations of PM2.5, suggesting the high abundance of soil dust in this fraction can be seen.

Scientists advise people to avoid going on walks early in the morning since they could be subject to even higher levels of contamination. High industrial and vehicular emissions, combined with biomass burning in the surrounding areas, cause more pollution to be stuck due to the valley effect and inversion in major cities in this zone, such as Delhi and Mumbai. On the other hand, as from the survey done in Delhi authors can conclude that people are merely less aware who are less educated and working in an industrial area. Merely men's are affected due to pollutants as the lifestyle and work they are inculcated in such regions.

\section{FUTURE SCOPE}

The users will be able to ascertain the likely impacts easily, at every corner of the road corridor. Thus, the model can be applied at any desired location to fetch the air quality data. Using the above requisite knowledge user can get the air quality data and relate it with the various health hazards, unlike conventional practices. The study can also focus on finding the choices of people to work indifferently soothing environment with less of the pollution which is tempting them to various hazardous diseases. As using the upgraded BHARAT standard vehicles, the engine can nebulize the pollutant emitting through them. Finding the way to rectify the pollutant at an early stage to make a healthy environment. With the help of the vehicle count from the satellite images and inducting ML one can determine the pollution from each vehicle and then with cumulative summation we get it for the region for that duration this work can be done in the future.

\section{ACKNOWLEDGEMENT}

The authors would like to thank Google, especially Google Maps, for allowing them access to their services so that they could create an air quality map of different cities without breaking any rules or policies. Also, the authors like to thank $\mathrm{CPCB}$ and NEERI for providing the open-sourced data using that mapping becomes easy and convenient.

\section{REFERENCES}

Babisch, Wolfgang, and Irene Van Kamp. 2009. "ExposureResponse Relationship of the Association between Aircraft Noise and the Risk of Hypertension." Noise and Health 11(44):161-68.

Banerjee, D., S. K. Chakraborty, S. Bhattacharyya, and A. Gangopadhyay. 2008. "Evaluation and Analysis of Road Traffic Noise in Asansol, West Bengal." Journal of the Institution of Engineers (India): Environmental Engineering Division 89(SEPT):9-16.

Bocher, Erwan, Gwenaël Guillaume, Judicaël Picaut, Gwendall Petit, and Nicolas Fortin. 2019. "Noisemodelling: An Open Source GIS Based Tool to Produce Environmental Noise Maps." ISPRS International Journal of Geo-Information 8(3).

Dubey, Rakesh, Shruti Bharadwaj, and Dr Susham Biswas. 2020. "Intelligent Noise Mapping Using Smart Phone on Web Platform." Proceedings of the 2020 International Conference on Smart Innovations in Design, Environment, Management, Planning and Computing, ICSIDEMPC 2020 69-74.
Esri, An. 2018. "ArcGIS Secure Mobile Implementation Patterns." (November).

Gupta, Suprakash, Pramod Kumar, and Gunda Yuga Raju. 2019. "Application of Satellite Data and GIS in Studying Air Pollutants in Tehran." International Journal of Occupational Safety and Ergonomics 43(1):5-6.

Jana, Ď., Roman Juras, Jan Horálek, Roman Juras, Jana Doubalov, and Jan Hor. 2018. "Using Satellite Data and Data Fusion Techniques for Air Quality Mapping “ Spatial Overview." (April):2-3.

Kumar, Amrit, Pradeep Kumar, Rajeev Kumar Mishra, and Ankita Shukla. 2018. "Study of Air and Noise Pollution in Mega Cities of India." 77-84.

Maguire, David J. 2016. "ArcGIS: General-Purpose GIS Software." Encyclopedia of GIS 1-8.

Ramos, R. V., and A. C. Blanco. 2019. "GEOSTATISTICS for AIR QUALITY MAPPING: CASE of BAGUIO CITY, PHILIPPINES." International Archives of the Photogrammetry, Remote Sensing and Spatial Information Sciences - ISPRS Archives 42(4/W19):353-59.

Society, Rizvi Education. 2014. "Study of Noise Levels in Mumbai on Diwali Festival Day and Night Study of Noise Levels in Mumbai on Diwali Festival.” (January 2012).

Tandel, Bhaven, and Dipeshkumar Sonaviya. 2018. “A Quick Review on Noise Propagation Models and Software." (February):6.

Tian, J., and D. M. Chen. 2007. "Evaluating Satellite-Based Measurements for Mapping Air Quality in Ontario, Canada." Journal of Environmental Informatics 10(1):30-36. 